\title{
THE NATURE OF AESTHETICS: HOW CONSUMER CULTURE HAS CHANGED OUR NATIONAL PARKS
}

\author{
STEPHEN L. WEARING,* MATTHEW McDONALD, † JO ANKOR, \\ AND STEPHEN SCHWEINSBERG* \\ *University of Technology Sydney, Lindfield, Australia \\ †RMIT University, Vietnam, Ho Chi Minh City, Vietnam \\ ¥Flinders University, Adelaide, South Australia
}

\begin{abstract}
Tourism is essentially a modern Western social and cultural phenomenon, the analysis of which has evolved from premodernism through to postmodernism. Tourism differs significantly from nonWestern and historical forms of travel, being closely related to the emergence of modernity with the emphasis on economic viability and consumer culture. The massive growth of tourism over the 20th century and the emergence of a multibillion dollar global tourist industry have impacted on national parks as tourists increasingly seek nature-based experiences. This has occurred in conjunction with increases in leisure time, disposable income, technological improvements in communication and transportation, demographic changes, and a shift in the axis of personal identity and meaningful social action from production to consumption. This article examines how aesthetics fits into this evolution and the current role of national parks with a focus on the emergence of their production through the mass media to a consumer market. Finally, we propose more reflexivity in regards to tourism and place image production.
\end{abstract}

Key words: Aesthetics; Consumer culture; Landscape; National parks; Mass media

Introduction

In the late 19th century the early national parks of the US, Australia, Canada, and New Zealand were created in response to evolving societal constructs regarding our relationship with nature and wilderness. National parks are at their core environmental management instruments, created, in the words of the International Union for the Conservation of Nature (2014), to ensure that "natural or near natural areas [are] set aside to protect large-scale ecological processes, along with the complement of species and ecosystems characteristic of the area." However, since their initial establishment in the US at Yellowstone in 1872, national parks have also been intrinsically linked to evolving notions of what 
constitutes society and ways in which society may best interact with the natural world. Tourism is perhaps the most well-known of these social processes. The International Union for the Conservation of Nature (2014) notes that in addition to the aforementioned environmental preservation goals, parks must also provide a foundation for "environmentally and culturally compatible spiritual, scientific, educational, recreational and visitor opportunities.”

Humankind's relationship to wilderness has evolved over the 150-year history of the national parks movement. In Australia, authors including Hall (1992) have written of the way in that societal consciousness of the need for environmental preservation through parks and other protected areas has grown from the concern of a niche collection of environmental pioneers to being a concern for the wider community and policy makers. This evolving environmental consciousness stands in stark contrast to the anthropocentric concerns of early recreationalists who frequently saw the environment in parks, such as the Royal National Park south of Sydney, as a blank canvas for pursuing a range of "enlightened" pursuits including: croquet, cricket, boating, picnics, military tattoos, and the like. The wilderness with which these recreationalists were interacting is, we argue, a social construct in the sense that the characterization of a landscape as "wilderness" is made on the basis of a perceived lack of human intervention in the landscape. The manner with which society may attempt to exert control over wilderness is determined in part on the basis of broader societal processes that are particular to different regions of the world.

By way of example, it was the opening up of the US states of Montana and California to gold prospectors in the 1860s that first led to the establishment of national parks, including Yellowstone and Yosemite (Chittenden \& Bartlett, 1964; Doremus, 1999; Runte, 1997). Gold prospecting is an activity fundamentally connected to the historical development of the "frontier psyche" in the US (Babcock, 1949; Johnson, 2001). Drawing on the words of former editor of the Sacramento Placer Times Edward Kemble (1849, cited in Eifler, 2000) who wrote that within 1 year of the "discovery" of gold the characterization of the area as Sacramento city is "no misnomer. . . . The river's side presents a scene of admirable city-like confusion” (p. 192).
Such a characterization, Eifler (2000) notes, is not at odds with our understanding of wilderness in the sense that wilderness "need not be confined only to the land and its resources. In many ways the frontier towns presented bewildering situations to their earliest residents” (p. 192).

The idea that the natural world may lead to bewilderment by those that seek to interact with it is not new. The creation of the US National Park Service is said to have emerged from the confluence of a range of societal and environmental forces- "the religious naturalism of Thoreau and Emerson, romanticism in the arts and early nostalgia for what was obviously the end of untamed wilderness" (Sax, 1980, p. 7). Leopold (1968) wrote that the "ability to see the cultural value of wilderness boils down, in the last analysis, to a collection of intellectual humility" (p. 200). The societal forces that pushed for the conservation of wild areas (or what eventually became known in the US after 1916 as the "National Parks movement") saw their use by the public for spiritual inspiration, solitude, and the maintenance of physical health and well-being. From a political perspective, not only did the protection and conservation of pristine natural environments provide a vital public recreation resource, they also became a symbol of national pride and cultural superiority (Nash, 1967). The present authors do not dispute that national parks may indeed have such values. However, we do wish to suggest that our ability to understand consumer culture in national parks cannot be limited to simple analyses of purchase intent, tourist motivations, and the other concerns of tourism in neoliberal market economies. Instead, there is necessity to understand such forces in the context of the way in which the wilderness area itself gives definition and meaning to the human enterprise (Leopold, 1968).

In the present article we will consider the role of media in the marketing of national parks to an increasingly diverse population. Films have the potential to capture the essence of what characterizes parks to various stakeholder groups. The recent National Parks Experience film series (see http:// npexperience.com/), by way of example, seeks to tell the stories of individual park users in the hope that they can encourage a broader section of the population to make themselves part of the national park story. While this is the ideal, the use of mass 
media by tourism interests too often defines their goals solely in terms of the potential for economic return from their marketing to consumers.

Such environmental commodification runs the risk of glossing over the symbolic complexities that characterize society's perceived value in the natural world. Our relationship with national parks has always been complex, with preservation and conservation balanced against recreation and tourism use. A commodification of the aesthetic of landscape, combined with processes used to attract visitors/tourists to areas of natural wilderness, sees mass media becoming central to expectations of national parks. We must, in the words of Leopold (1968), avoid becoming like the "shallow-minded man (sic) who has lost his rootage in the land [and] assumes that he has already discovered what is important” (p. 200). Instead, there is a necessity to begin a discussion of how media can better appreciate the complexities of parks and become reflexive to the concerns of wider society in the manner in which they present the landscape of parks to the world. We start with understanding aesthetics as a concept before relating this to consumer culture and the experience of place.

\section{Aesthetics and Landscape}

The concept of assigning areas of land for preservation in their natural state and for the future benefit of society grew out of both 19th century artistic Romanticism and the emergence of the naturalist sciences. The relationship of external objects to inner values is the essence of the aesthetic: magnificent mountains and a sense of wonder, the grandeur of a thunderstorm, and a sense of humility and awe that such powerful natural processes instill in people. During the 18th and 19th centuries Western artists began to popularize the spiritual, restorative, health-giving benefits of natural settings. The backdrop of this emerging shift in cultural values was the industrial revolution, which heralded the unprecedented growth of cities, pollution, poverty, and dehumanizing labor. On this subject Mirams (2002) has identified the challenges that beset early environmental pioneers such as James Barrett as they fought against environmental land managers who at the time were primarily concerned with the utilitarian possibilities afforded by parks bordering urban areas. Such managers saw the potential in parks, such as the Royal National Park south of Sydney, in terms of the opportunities provided to see wildlife from other countries (notably deer), picnics, and other passive pursuits (Eastwood, 2014). While there is no doubt these areas are as valuable to large sections of the population then as they are now, Miram (2002) notes that such narrow views have the potential to gloss over the profound spiritual values that underpins humankind's connection to nature in many parts of the world (Broder, Collins, Holmgren, \& Macdonald, 2006; MilesWatson \& Miles-Watson, 2011; Singh \& Sharma, 2010). While Saunders (2013) notes that an ecological aesthetic has overtaken scenic aesthetic qualities as the predominant driver and rationale for appreciating and preserving nature, Tuan (1989) identifies the aesthetic experience as one that contains "an element of life-enhancing surprise” (p. 233)—we may be prepared yet it catches us unaware. This implies a personal engagement beyond mere activity, which sits outside ecological descriptions.

For many years writers, painters, and other artists have played an important role in the representation of various perspectives on the changing nature of the environment for human society and in particular the effect of industrialization and how it should respond (Ashton, 1968; Coleman, 1992; Wylie, 1989). Such an observation is important for the present discussion in the sense that how successful the media is in marketing a vision for national parks stems from their ability to tap into the sensibilities of the listening public. Robinson and Andersen (2002) talk of literature as being simultaneously an object or culture, a mechanism whereby culture may be created. Travel writing in mediums including poetry, novels, and popular magazines has the ability to inspire people to visit national parks. In this regard, Urry (1995) talks of the influence of poets such as Coleridge and Wordsworth on visitor interest in England's Lakes District. Similarly the environmental historian Runte (2002) talks eloquently of the ways in which magazines, including Life and the Saturday Evening Post, provided a source of inspiration for his mother to visit national parks, resulting in a renewed commitment to life that stemmed from her exposure to a "country as magnificent as it was healing” (p. 70).

In the foundational 1790 text on aesthetics, Critique of Judgment, Kant (1790/1987) argued that 
appreciation of the aesthetic is demonstrated by "taste," with some people having greater ability to discern and judge, and therefore name, such esoteric qualities than others (Leith, 2001). Like Kant, the social theorist Pierre Bourdieu (1984) conceptualized that one's ability to exercise good "taste" had become a marker of social status in modern society. Kant argued that the aesthetic exists in autonomy as an attribute of the object itself, and that the aesthetic is accessible only through separation from the mundane and worldly. Thus, a landscape can be properly appreciated only by some and only if viewed dispassionately. The Romantic period saw the aesthetic concept of beauty taken toward a more personal and passionate sense of the transcendent, itself a development of the idea of the sublime, and the linking these concepts specifically to nature. Both the art and literature of this period dramatize not only the sensual grandeur of vistas and episodes (e.g., mountains and valleys, storms and clouded skies, moonlight over seascapes and the like), but also the inward identity of response to these in the form of transcending the everyday into the realm of deeper meaning (Ferber, 2010). What was seen as sublime in nature lay outside reason, order, proportion, and balance-outside society and civilizing influences; it inspired awe, astonishment, humility (Leith, 2001). Concepts of the sublime and of humankind's need for the aesthetic served to increase awareness of diversity and the vulnerability of landscape to human exploitation. It was in this cultural environment that the idea of national parks was initiated.

However, as 20th century modernism developed, the idea of aesthetics as preexisting and selectively discernible was strongly challenged. The debate focuses on whether "aesthetic" can be held to be universal and timeless or if it is a politically influenced and historically created value system. Raymond Williams (1958, cited in Leith, 2001) suggests that the aesthetic is "a shifting historical product . . . a complex mutating human product linked with concepts [of] literacy, imagination, taste and beauty, all influenced by sociological conditions” (p. 1566). Bourdieu (1984) contends that aesthetic judgment, rather than being an expression of innate taste, is rather a process that both produces and legitimates economic and status inequalities and is socially produced in association with material goals. Shifts in the reputation of an object or site, such as a national park, reflect the continual jockeying for position, prestige, and status in a cultural economy in which different groups compete with each other to ascend a social and cultural hierarchy (Bourdieu, 1984).

There is selectivity involved in what people see, and the observations, and thereby knowledge, that are constructed from this. Meinig (1979) in The Beholding Eye: Ten Versions of the Same Scene makes this clear in relation to landscape. He suggests:

a simple exercise: take a small but varied group . . . and have each describe the landscape, . . . what it is composed of and something of the "meaning" of what can be seen. It will soon be apparent that even though we gather together and look in the same direction at the same instant, we will not-we cannot - see the same landscape. Thus we confront the central problem: any landscape is composed not only of what lies before our eyes but what lies within our heads. Recognition of this brings us to the brink of some formidably complex matters. We are concerned not with the elements but with the essence, with the organising ideas we use to make sense out of what we see. (p. 33)

In this way, it is inescapable that the visitor sees in the vista the aesthetics, values, governing ideas, and underlying philosophies of their culture (Meinig, 1979). Aesthetics, in this way, mediate the tourist's interpretation of the tourism landscape. Moreover, Jameson (1983) writes that we cannot return to aesthetics based on historical situations that are no longer ours; we are held to our current contexts. The expansion of capitalism has changed the values, uses, and even concepts of ownership of space, with spatial issues being the fundamental organizing concern of political cultures (McDonald \& Wearing, 2013; Soja, 1989). Postmodern engagement with place is narrative and social, differing from the 19th century aesthetic of transcendent and unreachable.

\section{Consumption and Consumer Culture}

While it can be therefore understood that tourism sites hold an aesthetic content that elicits a response from visitors, the cultural economy of place means that understanding aesthetics is not straightforward (see Sharp, 2007). In the context of the fashion industry, Entwistle (2002) notes that "economic calculations are entwined with cultural concerns, 
bound to forms of cultural knowledge, capital and acquired taste, and to social, cultural and institutional relations" (p. 317). Such concerns impact on the objects, subjects, and sites of consumption (McDonald \& Wearing, 2013) in the sense that beyond ensuring the basics of human life, consumption can be understood as a process not so much of acquiring objects but of changing our inner landscape-we are buying values and identities in the possessions and activities purchased, tourism being no lesser a part of this than clothing or furniture.

All tourists, regardless of their motivation, will involve themselves in a combination of effective and symbolic consumption (Gonçalves \& Thomas, 2012). Symbolic consumption has implications for a range of tourism management debates (e.g., the demonstration effect), in that so much of the way different tourism stakeholders relate can be connected to the purchase and enjoyment of goods for the construction of lifestyle and identity (Featherstone, 2001). Fisher (2004) notes that it is possible for the effect of one stakeholder on another to be indirect, through what he describes as an "informational cascade." For Fisher (2004), this involves one person in a host society copying the behavior of another individual who themselves has been earlier influenced by tourists. The motivations of tourists to visit national parks may in part be resultant from the cascaded influence of media progressively influencing small sections of society who in turn influence other sections of society with whom they come into contact. As DeGrazia (1996) notes, "there was nothing natural or inevitable about the development of modern consumption practices" (p. 3); the citizen had to be taught to become a consumer by learning how to identify, express, and satisfy long suppressed desires, to seek out new pleasures, to spend now and save later.

In its most basic form, media has been defined as "cultural technologies for the communication and circulation of ideas, information and meaning” (Barnett, 2009, p. 450). Pierre Nora (1996, cited in Reijnders, 2011) identifies places of the imagination as physical localities that function as a symbolic anchor for the collective imagination of a society. Indeed, throughout history, visual images have mediated interpretations of the world (Masuda, Gonzalez, Kwan, \& Nisbett, 2008). The act of capturing a scene, either with the eye, the brush, or the camera, is caught up in the cultural values, practices, habits, and norms of those who shape the scene, including its categorization as a park, and in the interpretation of visitors. Since their inception in America in the 1870s, national parks have been connected to the very basis of the American psyche with the US Senator Dianne Feinstein describing national parks as "America's cathedrals" (Feinstein, 2006). Such sentiments are influential in a marketing context as they provide a means for establishing a marketing segmentation framework for national parks where product offerings are linked to visitor motivations for experiencing various forms of recreation, spiritual enlightenment, cultural immersion, and the like. Over the course of the history of America's National Parks movement the nature of society's connection to wilderness has changed from one of fear, to exploitation, to reverence (Manning, 1989). The former CEO of the Canadian Pacific Railway (CPR) William Cornelius Van Horne is often attributed with the observation that "If we can't export the scenery, we'll import the tourists." The idea that not only are the attributes of a destination a significant determinant of tourist intent, though also that a tourist's views of a destination is a significant determining factor for the managers of a region who may be considering how best to develop a particular tourist product or service.

Giddens (2003) argues that the new freedoms associated with late modernity have resulted in consumers that are active, reflexive, knowing agents. We can place this shift toward coconsumption in relation to Lefebvre's (1974/1991) observation that capitalism has transformed space into a commodity, reproducing capitalist modes of production and consumption that shape the nature of social interactions and relations that occur in them. Active in this shift is has been the role of the mass media, especially the 21st century new social media. The mass media, of course, has been well documented as a form of image development, from art through to literature and film, and includes tourism marketing (Beeton, 2010). Film and television in particular play an important role in tourism as particularly powerful mediums (Churcher, 2003) that operate both on the visual and emotional level, consequently delivering strong images (Pritchard \& Morgan, 2000). It is well documented that film viewing creates visitation to viewed sights (Beeton 2008, 
2010; Croy, 2010) such as national parks. Selective image making for consumption forces places to evolve to meet the needs of tourists (Wirth \& Freestone, 2001); whole environments are restructured by tourism to make them more attractive for consumption. Places are redefined as commodities that can be bought and sold. While access and use of public spaces, such as national parks, has some legislative and management controls, this does not apply to film or television representations of place. The inconstant nature of the spatial images that project claims about a space, and the appropriation of these images by the users of those spaces (Zebracki, Van Der Vaart, \& Van Aalst, 2010), such as tourism operators, is uncontrolled.

The significance of visual images in advertising, promoting place selling, and place attachment, added to the traditional claims of aesthetics and collective memory, is a potent force (Zebracki et al., 2012). Commonly, an image defines what is beautiful, what should be experienced, and with whom one should interact (Dann, 1996). Consequently, film and television have encouraged visitation to many locations and have also determined to a degree the way we interact as a tourist. Wilderness activist and journalist Robert Sterling Yard in June 1916 penned the following statement for the article "Making a Business of Scenery":

We want our National Parks developed. We want roads and trails like Switzerland's. We want hotels of all prices from lowest to highest. We want comfortable public camps in sufficient abundance to meet all demands. We want lodges and chalets at convenient intervals commanding the scenic possibilities of all our parks. We want the best and cheapest accommodations for pedestrians and motorists. We want sufficient and convenient transportation at reasonable rates. We want adequate facilities and supplies for camping out at lowest prices. We want good fishing. We want our wild animal life conserved and developed. We want special facilities for nature study. (cited in Sellars, 2009, p. 28)

Indeed, Kotler (1975, cited in Lamb \& Crompton, 1981) defines marketing as a "philosophy about the relations an organisation should have with its markets and public” (p. 1). However, even with the range of alternative marketing strategies-ecological marketing, green marketing, and the like—we now have a system that in terms of practice and practicalities is providing images to the public, in order to entice them to visit the "nature" in parks, which present an aesthetic of nature and natural experiences. Today there is an explicit recognition of tourism and recreation that also provides a foundation for environmentally and culturally compatible spiritual, scientific, educational, recreational, and visitor opportunities (International Union for Conservation of Nature, 2014). The value positions that different tourism stakeholders attach to the role of tourism in national parks illustrate the increasing trend towards seeing tourism as part of a larger system of sociocultural, environmental, and other influences within national park management. Any commercial aspect of place and the marketing of place is embedded in a complex web of emotional, situated, and localized experiences.

The ordering practices of consuming nature that apply through place management and place representation in images in fact reflect a contingent relation between image and viewer (Cataldi, Kelly, Kuzmich, Maier-Rothe, \& Tang, 2011) and this aligns with Kant's understanding that perception requires internal conditions for successful appreciation of the external.

\section{Experiences}

While individuals have an individual aesthetic perception of national parks, this perception appears to be increasingly influenced by the mass media. The following discussion focuses on the actual onsite experience suggesting it has the potential to be deflating due to not only the mediatized imagery of nature, though more importantly due to the mediatized experiences that occur because of it. Saunders (2013) notes: “Aesthetic views about nature are not views from nowhere . . . they are constructed by our particular emotional response and cultural/scientific knowledge, lived experience, mediated through our sensory experience and motivated by our interests" (p. 7).

Images play a major role in the mediation of visual sensory experience in asserting a prior aesthetic on a forthcoming physical in-place experience. In the images of experiences provided in film/ television tourism, for example, we see the "David Attenborough Effect," which is found to perpetuate tourists' expectations of close encounters with wild 
animals. David Attenborough is part of the world of celebrity conservationists that offer "closeness to nature and experience of the same" (Brockington 2008, p. 551). In particular, his documentaries fail to detail the months or years of research into a particular population of animals, the hours of (often extremely uncomfortable) filming required to "get the shot," nor the negotiations and hours of traveling undertaken to reach such unchartered destinations (de la Torre, Snowdon, \& Bejarano 1999). An example of this is the first-ever filming of a snow leopard, which took 2 years of planning and months staking out different sites in the mountains of northern Pakistan by highly experienced zoologists and photographers. Consequently, Attenborough's documentaries can convey the wrong message of wild animals and their willingness to connect with humans in nonthreatening ways (de la Torre et al., 1999). We argue that this "David Attenborough Effect" has influenced even captive animal viewing, and overall has created unreasonable expectations of viewing animals in close proximity, which the tourist seeks and expects when wildlife viewing (Brockington, 2008; de la Torre et al., 1999; Wearing, Buchmann, \& Jobberns 2011). This is the more problematic as film tourism research has demonstrated how even highly contrived situations may be experienced and treasured as "authentic" encounters (Buchmann, Moore, \& Fisher, 2010), available on demand. The aesthetic here is not of grandeur, though of the human relation with other living creatures. It is a subtle variation of the Western imperial gaze, of privileged position.

The symbiotic complexity mentioned at the start of this article is not present or presented in such film images; although Attenborough consistently voices an awe of the world he is viewing, it is also consistently explained and rationalized in a particular natural science vernacular. It is rare that the lives of the people who live in these spaces are realized as part of the complex web of existence. The touristic sign is coded in the language of aesthetics; indeed, the pairing of tourism and aesthetics is so tight that one could not exist without the other (see Knudsen, Metro-Roland, and Rickly article in this issue). Tourism imagery filters out what is not held to be an inducement to visitation, often quite literally through image manipulation. When visitors then arrive at the chosen destination, the presented reality reflects management issues, economic imperatives - and aesthetics come some way down the list.

\section{Conclusion}

As stated at the beginning of our discussion, Kant (1790/1987) argued that appreciation of the aesthetic is demonstrated by "taste," with some people having greater ability to discern and judge, and therefore name, such esoteric qualities than others (Leith, 2001). Tourism image makers, including the documentaries of exotic locales and wildlife, choose and manipulate what is presented from a standpoint of "greater" knowing about places and experiences on offer, and we as tourism consumers accept that position-we trust what we are given. Kant's (1790/1987) consideration that the aesthetic exists in autonomy as an attribute of the object itself is also perpetuated, through the isolation of image from context in the practice of marketing landscapes and sites, including the natural features in National Parks across the world. His third consideration, that the aesthetic is accessible only through separation from the mundane and worldly, is a recurring theme in tourism marketing -we are all familiar with the notion of escape and relaxation propounded in many campaigns and promotions.

Yet, we contend, the consumers and the managers of tourism in national parks have evolved in their understanding of place needs as well as human engagement in parks - in short, in the aesthetics of the natural world and humanity's need to realize, respect, and engage with symbiotic complexity.

Perhaps it is time for media producers and presenters to become a little reflexive in the production of tourism and place images.

\section{References}

Ashton, T. S. (1968). Iron and steel in the industrial revolution (Vol. 2) Manchester: Manchester University Press.

Babcock, C. M. (1949). The social significance of the language of the American frontier. American Speech, 256-263.

Barnett, C. (2009). Media. In R. J. Johnston, D. Gregory, G. Pratt, M. Watts, \& S. Whatmore (Eds.), The dictionary of human geography (5th ed., p. 450). Oxford: Blackwell Publishers.

Beeton, S. (2008). From the screen to the field: The influence of film on the tourism and recreation. Tourism Recreation Research, 33(1), 39-47. 
Beeton, S. (2010). The advance of film tourism, Tourism and Hospitality Planning \& Development, 7(1), 1-6.

Bourdieu, P. (1984). Distinction: A social critique of the judgement of taste (R. Nice, Trans.). London: Routledge \& Kegan Paul.

Brockington, D. (2008). Powerful environmentalism: Conservation, celebrity and capitalism. Media, Culture and Society, 30(4), 551-568.

Broder, O., Collins, M., Holmgren, V., \& Macdonald, A. (Eds.). (2006). And they're still falling: Women's voices from the NSW southeast rorests. Canberra: Ginninderra Press.

Buchmann, A., Moore, K., \& Fisher, D. (2010) Experiencing film tourism: Authenticity and fellowship. Annals of Tourism Research, 37(1), 229-248.

Cataldi, M., Kelley, D., Kuzmich, H., Maier-Rothe, J., \& Tang, J. (2011) Residues of a DreamWorld: The high line. Theory, Culture \& Society, 28(7-8), 358-389.

Chittenden, H. M., \& Bartlett, R. A. (1964). The Yellowstone National Park. Norman, OK: University of Oklahoma Press.

Churcher, M. (2003). Acting for film: Truth 24 times a second. London: Virgin Books.

Coleman, D. C. (1992). Myth, history and the industrial revolution. London: Bloomsbury Publishing.

Croy, W. G. (2010). Planning for film tourism: Active destination image management. Tourism and Hospitality, Planning and Development, 7(1), 21-30.

Dann, G. (1996). Tourists' images of a destination-an alternative analysis. Journal of Travel \& Tourism Marketing, 5(1-2), 41-55.

DeGrazia, D. (1996). Taking animals seriously: Mental life and moral status, Cambridge: Cambridge University Press.

de la Torre, S., Snowdon, C. T., \& Bejarano, M. (1999). Preliminary study of the effects of ecotourism and human traffic on the howling behavior of red howler monkeys, Alouatta senicuius, in Ecuadorian Amazonia. Neotropical Primates, 7, 84-86.

Doremus, H. (1999). Nature, knowledge and profit: The Yellowstone bioprospecting controversy and the core purposes of America's national parks. Ecology Law Quarterly, 26, 401.

Eastwood, K. (2014). Rethinking national parks. Australian Geographic, 123, 74-87.

Eifler, M. A. (2000). Taming the wilderness within: Order and opportunity in gold rush Sacramento, 1849-1850. California History, 192-207.

Entwistle, J. (2002). The aesthetic economy: The production of value in the field of fashion modelling. Journal of Consumer Culture, 2(3), 317-339.

Featherstone, M. (2001). Consumer culture. In N. J. Smelser \& P. B. Baltes (Eds.), International encyclopaedia of the social \& behavioral sciences (pp. 2662-2669). Amsterdam: Elsevier.

Feinstein, D. (2006). Senator Feinstein Warns Against Proposed Revisions to National Park Service. Retrieved from http://www.feinstein.senate.gov/public/index.cfm/ press-releases?ID=792A0162-7E9C-9AF9-75DE6FF377DEF008
Ferber, M. (2010). Romanticism: A very short introduction. Oxford: Oxford University Press.

Fisher, D. (2004). The demonstration effect revisited. Annals of Tourism Research, 31(2), 428-446.

Giddens, A. (2003). An interview with Anthony Giddens. Journal of Consumer Culture, 3(3), 387-399.

Gonçalves, A., \& Thomas, H. (2012). Waterfront tourism and public are in Cardiff Bay and Lisbon's Park of Nations. Journal of Policy Research in Tourism, Leisure and Events, 4(3), 327-352.

Hall, C. M. (1992). Wasteland to world heritage: Preserving Australia's wilderness. Carlton: Melbourne University Press.

International Union for Conservation of Nature. (2014). Protected areas category II. Retrieved from http://www.iucn. org/about/work/programmes/gpap_home/gpap_quality/ gpap_pacategories/gpap_pacategory2/

Jameson, F. (1983). Post-modernism and consumer society. In H. Foster (Ed.), Post-modern culture (pp. 111-125). London: Pluto Press.

Johnson, S. L. (2001). Roaring camp: The social world of the California gold rush: New York: WW Norton \& Company.

Kant, I. (1987). Critique of judgment (W. S. Pluhar, Trans.). Indianapolis, IN and Cambridge: Hackett Publishing Co. (Original work published 1790)

Lamb, C. W., \& Crompton, J. L. (1981). The status of the marketing concept in public recreation and park agencies. Journal of the Academy of Marketing Science, 9(1), 1-14.

Lefebvre, H. (1974/1991). The production of space (D. Nicholson-Smith, Trans.). Oxford, UK: Blackwell.

Leith, V. B. (Ed.). (2001). The Norton anthology of theory and criticism. New York: WW Norton \& Company.

Leopold, A. (1968). A sand county almanac and sketches here and there. Oxford: Oxford University Press.

Manning, R. E. (1989). Nature of America: Visions and revisions of wilderness. The Natural Resources Journal, 29(1), 25-40.

Masuda, T., Gonzalez, R., Kwan, L., \& Nisbett, R E. (2008). Culture and aesthetic preference: Comparing the attention to context of East Asians and America. Personality and Social Psychology Bulletin, 34, 1260.

McDonald, M., \& Wearing, S. (2013). Social psychology and theories of consumer culture: A political economy perspective. London: Routledge.

Meinig, D. W. (1979). The beholding eye: Ten versions of the same scene. In D. W. Meinig (Ed.), The interpretation of ordinary landscapes. Oxford: Oxford University Press.

Miles-Watson, J., \& Miles-Watson, S. (2011). Conflicts and connections in the landscape of the Manimahesh pilgrimige. Preliminary Communication, 59(3), 319-333.

Mirams, S. (2002). For their moral health: Urban progressive ideas and national park reservation in Victoria. Australian Historical Studies, 33(120), 249-266.

Nash, (1967). Wilderness and the American mind. New Haven: Yale University Press.

Pritchard, A., \& Morgan, N. J. (2000). Constructing tourism landscapes: Gender, sexuality and space. Tourism Geographies, 2(2), 115-139. 
Reijnders, S. (2011). Places of the imagination: Media, tourism and culture. Farnham, UK: Ashgate.

Robinson, M., \& Andersen, H. (2002). Reading between the lines: Literature and the creation of touristic spaces. In M. Robinson \& H. Andersen (Eds.), Literature and tourism (pp. 1-38). London: Continuum.

Runte, A. (1997). National parks: The American experience. Location. Lincoln, NE: University of Nebraska Press.

Runte, A. (2002). Why national parks? Retrieved from http://www.georgewright.org/192runte.pdf

Saunders F P. (2013). Seeing and doing conservation differently: A discussion of landscape, aesthetics, wilderness, and biodiversity conservation. The Journal of Environment Development, 22(1), 3-24.

Sax, J. L. (1980). Mountains without handrails, reflections on the National Parks. Michigan, MI: University of Michigan Press.

Sellars, R. W. (2009). Preserving nature in the national parks: A history. New Haven, CT: Yale University Press.

Sharp, J. (2007). The life and death of five spaces: Public art and community regeneration in Glasgow. Cultural Geographies, 14(2), $274-292$
Singh, R., \& Sharma, S. (2010). The Green Hiker Attitude Slowly Picks Up at ManiMahesh. Himalayan Highlights, 3, 2-4.

Soja, E. (1989). Postmodern geographies: The resassertion of space in critical social theory. London: Verso.

Tuan, Y. (1989). Surface phenomena and aesthetic experience. Annals of the Association of American Geographers, 79(2), 233-241.

Urry, J. (1995). Consuming places. London: Routledge.

Wearing, S. L., Buchmann, A., \& Jobberns, C. (2011). Free Willy: The whale-watching legacy. Worldwide Hospitality and Tourism Themes, 3(2), 127-140.

Wirth, R., \& Freestone, R. (2001) Tourism, heritage and authenticity: State-assisted cultural commodification in suburban Sydney, Australia. Urban Perspectives, 3(1), 10.

Wylie, I. (1989). Young Coleridge and the philosophers of nature. Oxford: Oxford University Press.

Zebracki, M., Van Der Vaart, R., \& Van Aalst, I. (2010). Deconstructing public artopia: Situating public-art claims within practice. Geoforum, 4(1), 786-795. 